\title{
SISTEMÁTICA GENÉRICA NO SUPORTE À PESQUISA BIBLIOMÉTRICA ILUSTRADA À AVALIAÇÃO DE DESEMPENHO ORIENTADA ÀS QUESTÕES REFERENTES AO DESENVOLVIMENTO SUSTENTÁVEL
}

\section{A GENERIC SYSTEMATIC TO SUPPORT BIBLIOMETRIC RESEARCH ILLUSTRATED FOR THE PERFORMANCE EVALUATION OF SUSTAINABLE DEVELOPMENT ISSUES}

\author{
Fabrício Kurman Merlin* E-mail: merlin.fabricio@gmail.com \\ Juliane Vieira de Souza* E-mail: juliane.vieiradesouza@gmail.com \\ Leonardo Ensslin* E-mail: leonardoensslin@gmail.com \\ Vera Lúcia Duarte do Valle Pereira* E-mail: vpereira@deps.ufsc.br \\ Sandra Rolim Ensslin* E-mail: sensslin@gmail.com \\ *Universidade Federal de Santa Catarina, Florianópolis, SC.
}

\begin{abstract}
Resumo: A questão que se apresenta, neste trabalho, é como selecionar o referencial teórico alinhado à pesquisa, que seja cientificamente justificada. Assim, este estudo, de caráter exploratóriodescritivo, objetiva apresentar e ilustrar um processo estruturado (ProKnow-C) para a seleção de artigos científicos sobre a avaliação de desempenho orientada às questões referentes ao desenvolvimento sustentável. A partir do processo proposto, citam-se os seguintes resultados: identificação de sete palavras-chave de pesquisa; identificação de 4 bases de dados de textos completos e resumos alinhados com o tema; seleção de 9.123 artigos que tratam do tema; filtragem estruturada dos 9.123 artigos selecionados nas bases de dados em 13 artigos científicos, que resultaram na sustentação teórica para a pesquisa sobre avaliação de desempenho no contexto do desenvolvimento sustentável.Na seqüência, identificou-se o perfil bibliométrico do portfólio bibliográfico selecionado, evidenciando as palavras-chave, os autores, artigos e periódicos dos artigos do portfólio e das referências do portfólio bibliográfico para os três últimos. Diante dos resultados, argumenta-se que o processo proposto se mostrou robusto, uma vez que conseguiu atingir o objetivo de identificar e selecionar as publicações relevantes para o estudo, a fim de reunir um conteúdo científico alinhado ao assunto que a pesquisa buscou tratar.
\end{abstract}

Palavras-chave: Desenvolvimento Sustentável. Avaliação de Desempenho. Portfólio Bibliográfico. Bibliometria. ProKnow-C.

\begin{abstract}
The question that arises in this work is how to select a theoretical structure scientifically justified to a research. Thus, this exploratory and descriptive study aims to present and illustrate a structured process (ProKnow-C) for selecting papers on performance evaluation oriented to issues concerning sustainable development. From the proposed process, it was mentioned the following results: identification of seven key words for search, identification of four databases of abstracts and full texts aligned with the research theme, selection of 9123 articles dealing with the theme; structured filtering of the 9123 selected articles from the databases in 13 scientific articles, which resulted in the theoretical underpinning for research on performance appraisal oriented to sustainable development issues. Subsequently, it was identified the bibliometric profile of the bibliography portfolio selected, highlighting the keywords, authors, journal articles and the articles of the portfolio and the portfolio of bibliographic references for the last three. Considering the results, it was argued that the proposed process was robust, since it achieved the goal of identifying and selecting relevant publications for the study, to gather scientific content aligned to the subject that the research sought to address.
\end{abstract}


Keywords: Sustainable Development. Performance Evaluation. Bibliographic portfolio. Bibliometrics. Proknow-C.

\section{INTRODUÇÃO}

A ciência do desenvolvimento sustentável é motivada por questões fundamentais sobre as complexas interações entre natureza e a sociedade (CARPENTER et al., 2006). Com o advento da revolução industrial, a implantação de técnicas de produção e de um modo de consumo predatório, vem provocando um grande impacto tanto nas relações estabelecidas entre os seres humanos quanto nas atividades humanas sobre o meio ambiente, dando origem a problemas críticos, dentre os quais, cita-se a degradação dos recursos naturais. Entretanto, até a metade do século $\mathrm{XX}$, a degradação dos serviços prestados pela natureza, tais como ar puro, água potável, solos férteis etc., se apresentava como um problema de caráter setorial, não interferindo como um fator limitante, seja na área econômica ou de decisão política do processo de desenvolvimento dos países que alcançaram um elevado grau de industrialização (ALMEIDA, 2007; MEA, 2005). A degradação desses serviços vem sendo acentuada nos últimos 50 anos, sobretudo pelos modelos de crescimento adotados pelas principais potências econômicas no mundo (MEA, 2005).

Um pesquisador, para iniciar a sua pesquisa científica, precisa selecionar um referencial teórico alinhado com o problema a ser estudado. No Brasil, atualmente, o Portal Capes disponibiliza um universo de 26.372 títulos para pesquisa, distribuídos em diversas áreas do conhecimento, em 130 bases de dados (CAPES, 2010). Para Krzyzanowski (1998, p.1), "[a] proliferação de títulos de periódicos nas diversas áreas do conhecimento tem sido objeto de preocupação dos profissionais que se interessam pela qualidade da informação científica". Para Souza (2010), essa preocupação aflige a comunidade científica e, em especial, os pesquisadores que são os responsáveis pela seleção do portfólio de artigos que fundamentam a pesquisa e que possuem uma visão holística e/ou específica do tema pesquisado.

Na seleção do portfólio bibliográfico para a realização da pesquisa científica, os pesquisadores trazem uma série de delimitações e dificuldades. Como exemplo, pode se citar o tempo disponível para a realização da pesquisa; o acesso a base de dados; a proliferação do tema pesquisado; a identificação dos artigos, autores e 
periódicos em destaque, relacionados ao tema de pesquisa; o viés do pesquisador, dentre outros.

Diante desse contexto, surge o seguinte problema de pesquisa: como construir o conhecimento necessário para iniciar uma pesquisa sobre avaliação de desempenho orientada às questões referentes ao desenvolvimento sustentável, segundo as delimitações do pesquisador? É importante explicitar que o conhecimento a ser construído, deverá ser entendido em termos de artigos, periódicos, autores e palavras-chave identificados, a partir do portfólio bibliográfico selecionado.

Assim, o objetivo geral da pesquisa consiste em construir, no pesquisador, o conhecimento em termos de periódicos, artigos, autores e palavras-chave, a partir do portfólio identificado. Para possibilitar o alcance do objetivo geral, os objetivos específicos são os seguintes: i) Seleção do portfólio bibliográfico; e, ii) Análise bibliométrica.

O meio a ser utilizado, que possibilitará alcançar o objetivo proposto, é o processo estruturado de busca do referencial teórico denominado ProKnow-C, proposto pelo Laboratório Multicritério de Apoio à Decisão (LabMCDA). Este processo foi escolhido devida a sua valia para trabalhos já realizados em temas variados de pesquisa, tais como evidenciação ambiental (ROSA, ENSSLIN, ENSSLIN, 2009); avaliação de desempenho organizacional (BORTOLUZZI et al., 2011); e,avaliação de programas de treinamento (TASCA et al., 2010). O processo visa auxiliar o pesquisador: i) na escolha das palavras-chave; ii) na escolha das bases de dados; iii) na seleção do portfólio bibliográfico; iv) na análise bibliométrica dos artigos, traçando o perfil de um portfólio de artigos científicos no contexto estudado (TASCA et al., 2010).

A pesquisa se justifica pela contribuição prática e teórica ao tema de avaliação de desempenho orientada às questões referentes ao desenvolvimento sustentável: teórica por fornecer um perfil dos artigos científicos que tratam sobre o tema; prática pela disponibilização de um processo que possibilita identificar, filtrar e quantificar por meio de critérios pré-estabelecidos, justificados cientificamente, artigos para a elaboração do referencial teórico de pesquisa.

O presente trabalho foi estruturado em quatro seções. Esta Introdução, de caráter preliminar, insere o leitor no contexto investigativo proposto no trabalho. A 
Seção 2 apresenta o constructo teórico. Na seção 3, a Metodologia da Pesquisa está dividida em duas partes, que apresentam, respectivamente, i) o enquadramento metodológico e ii) os procedimentos metodológicos com base no método ProKnow-C (BORTOLUZZI et al., 2011; LACERDA, ENSSLIN e ENSSLIN, 2011; TASCA et al., 2010). A seção 4 apresenta a ilustração do processo de seleção do constructo teórico de pesquisa, análise e discussão dos resultados. A seção 5 apresenta as considerações finais, fazendo recomendações para futuras pesquisas, com base nas limitações e delimitações do estudo atual.

\section{CONSTRUCTO TEÓRICO}

A literatura especializada que trata sobre o desenvolvimento sustentável, sobretudo a que se destina à avaliação de desempenho das questões orientadas a esse tema, atualmente, é bastante ampla. As questões abordadas envolvem uma miríade de contextos e situações, de variados níveis de complexidade (fenômenos, dimensões de análise, atores envolvidos, abrangência, espaço, tempo, etc.), exigindo a interação entre diversos campos do conhecimento. Trabalhos de autores como Carson (1962), Meadows et al. (1972), Sachs (1993, 2002) e Elkington (2004) são algumas das fontes clássicas geralmente utilizadas na familiarização, orientação e/ou suporte para a discussão dessas questões.

A obra de Carson (1962), Silent Spring, contribuiu para despertar a atenção sobre os problemas ambientais advindos do uso desenfreado da tecnologia, por parte da indústria química, para aumentar os ganhos em produtividade no campo, em especial com o uso de pesticidas e herbicidas. A obra atentou, também, para o despreparo das autoridades públicas para o controle e os impactos do uso intensivo desses produtos na saúde do Homem e suas implicações na natureza.

A obra de Meadows et al. (1972), Limits to Growth (LtG), encomendada pelo Clube de Roma, trata sobre a análise da problemática mundial usando um modelo de computador chamado World3, desenvolvido no Massachusetts Institute of Technology (MIT), integrando a economia mundial e o meio ambiente. Tal modelo permitiu examinar as interações de cinco subsistemas do sistema econômico global: população, produção de alimentos, produção industrial, poluição e consumo de recursos naturais não-renováveis. A contribuição desse trabalho está na 
popularização do debate sobre as questões ambientais e do desenvolvimento sustentável, sobre a previsão pessimista, apresentado pela modelagem LtG, que o crescimento contínuo da economia mundial excederia os limites planetários em algum momento do século XXI, resultando, provavelmente, no colapso da população e do sistema econômico. No entanto, o colapso poderia ser evitado com uma combinação de mudanças, com antecedência, no comportamento, na política e tecnologia.

Sachs $(1993,2002)$, em seu relatório sobre os resultados do Grande Encontro da Terra, realizado na cidade de Rio de Janeiro em 1992 (ECO 92), sob a coordenação da Organização das Nações Unidas (ONU), declarou que o planejamento do desenvolvimento sustentável, em nível global, deve contemplar, simultaneamente, cinco dimensões, conforme apresentado no Quadro 1.

Quadro 1 - As cinco dimensões do desenvolvimento sustentável propostas por Sachs

\begin{tabular}{|c|l|}
\hline Dimensões & \multicolumn{1}{|c|}{ Descrição } \\
\hline Social & $\begin{array}{l}\text { Faz menção, principalmente, à questão para quem é o desenvolvimento e quem } \\
\text { serão os beneficiados do programa. }\end{array}$ \\
\hline Econômica & $\begin{array}{l}\text { Muda o paradigma econômico para discutir que os benefícios sociais, ambientais e } \\
\text { humanos deveriam ser o centro da economia. }\end{array}$ \\
\hline Ecológica & $\begin{array}{l}\text { Declara que desenvolvimento e preservação ambiental são duas faces da mesma } \\
\text { moeda que deveriam ser vistas como complementares, e não contraditórias. }\end{array}$ \\
\hline Espacial & $\begin{array}{l}\text { Refere-se à discrepância econômica entre o Norte e Sul, sugerindo que as } \\
\text { disparidades entre as regiões devem ser reduzidas. }\end{array}$ \\
\hline Cultural & $\begin{array}{l}\text { Refere-se ao reconhecimento da importância das culturas locais e ostilos } \\
\text { endógenos para com a modernidade. Declara que o desenvolvimento não pode ser } \\
\text { imposto por forças exógenas, e sim, deveria vir das forças endógenas. }\end{array}$ \\
\hline
\end{tabular}

Fonte: Adaptado de Sachs (1993; 2002)

Merlin (2011) observa que as dimensões estabelecidas por Sachs (1993, 2002), bem como as descrições das preocupações abordadas, têm um caráter governamental, ou seja, foram elaboradas para orientar os órgãos responsáveis em conduzir o planejamento do desenvolvimento sustentável com vistas às nações. No entanto, não impede que também possam ser utilizadas pela iniciativa privada.

Elkignton (2004), a quem, geralmente, é atribuída a difusão do Triple Bottom Line (TBL), tanto no meio acadêmico quanto no corporativo, considera o desenvolvimento sustentável composto por três grandes dimensões (econômica, social e ambiental) a serem levadas em conta pelas organizações. A influência do 
TBL estimulou suas atividades e gerou ferramentas que puderam produzir expressões quantificáveis, em termos de desempenho, para cada uma das dimensões. Algumas das ferramentas de gerenciamento foram construídas nas bases do TBL, tais como o Global Reporting Initiative (GRI), o SIGMA Project e o Bovespa Corporate Sustainability Index (ISE) (ADAMS 2004; ELKINGTON, 2004; SUSTAINABILITY COMPENDIUM, 2007). O Quadro 2 apresenta algumas das questões tratadas em cada uma das dimensões do TBL.

Quadro 2 - Questões relevantes às organizações em cada uma das três dimensões do TBL

\begin{tabular}{|c|c|c|}
\hline Dimensão & Categoria & Aspecto \\
\hline Econômica & $\begin{array}{l}\text { Impactos } \\
\text { Econômicos Diretos }\end{array}$ & $\begin{array}{l}\text { Clientes; Fornecedores; Funcionários; Provedores de capital; } \\
\text { Setor Público. }\end{array}$ \\
\hline Ambiental & Ambiental & $\begin{array}{l}\text { Material; Energia; Água; Biodiversidade; Emissões; Efluentes; } \\
\text { Resíduos; Suprimentos; Produtos e Serviços; Transporte; } \\
\text { Conformidade. }\end{array}$ \\
\hline \multirow{4}{*}{ Social } & Práticas de Trabalho & $\begin{array}{l}\text { Emprego; Relações Trabalhistas; Saúde e Segurança; } \\
\text { Treinamento e Educação; Diversidade e Oportunidade. }\end{array}$ \\
\hline & Direitos Humanos & $\begin{array}{l}\text { Estratégia e Gestão; Não discriminação; Liberdade de } \\
\text { Associação e Negociação Coletiva; Trabalho Infantil; Trabalho } \\
\text { Forçado e Compulsório; Práticas Disciplinares; Práticas de } \\
\text { Segurança; Direitos Indígenas. }\end{array}$ \\
\hline & Sociedade & $\begin{array}{l}\text { Comunidade; Corrupção e Suborno; Contribuição Política; } \\
\text { Concorrência e Preço. }\end{array}$ \\
\hline & $\begin{array}{l}\text { Responsabilidade } \\
\text { sobre o Produto }\end{array}$ & $\begin{array}{l}\text { Saúde e Segurança do Cliente; Produtos e Serviços; } \\
\text { Propaganda; Respeito pela Privacidade. }\end{array}$ \\
\hline
\end{tabular}

Fonte: Adaptado de GRI (2002)

Além desses autores, há diversos outros que contribuem com estudos na temática do desenvolvimento sustentável, sob diferentes perspectivas, sejam estas relacionadas com a dimensão econômica, como fazem, por exemplo, Bruno e Bruno (2009), Rees (2003), Salih (2003) e Morioka (2006); sejam relacionadas com a dimensão social, como fazem, por exemplo, Trim e Lee (2007), Byrd (2007) e Aguirre (2002); ou ainda, sejam relacionadas com a dimensão ambiental, como fazem, por exemplo, Davidson e Lorrel (2001), Nogueira et al. (2011), Sharfman et al. (2004) e Valente (2005). Há trabalhos que examinam o conceito de desenvolvimento sustentável e os movimentos sociais que o influencia, tais como o de Estes (1993), Faber et al. (2005) e Pezzey (1992). Há trabalhos que discutem sobre as diferenças entre crescimento e desenvolvimento, tais como o de Sachs (1993, 2004) e Veiga (2008). Há também, trabalhos que clamam por ferramentas de 
gestão para o desenvolvimento sustentável, tais como Carpenter et al., (2009), Zwetsloot (2003) e Jorgensen et al. (2006), e trabalhos que apresentam ferramentas destinadas à avaliação do desenvolvimento sustentável, tais como Ferroli e Librelloto (2011), Reed et al. (2006), Robèrt et al. (2002) e Sustainability Compendium (2007).

Como pode ser percebido, abordar o tema desenvolvimento sustentável já é, por si só, um grande desafio, devido à abrangência das questões envolvidas. Esse desafio aumenta para o pesquisador, ao deparar-se com a quantidade e variedade de trabalhos já publicados, principalmente no que se refere a sua avaliação, devido à falta de consenso sobre o seu conceito, conforme atestam Faber et al. (2005) e Kates et al. (2005), dificultando a sua operacionalização, além das particularidades dos contextos nos quais é avaliado.

\section{METODOLOGIA}

Esta seção do trabalho aborda: i) o enquadramento metodológico e ii) os procedimentos metodológicos.

\subsection{Enquadramento Metodológico}

Observaram-se as seguintes dimensões,para a apresentação do enquadramento metodológico da presente pesquisa: i) natureza do objetivo; ii) natureza da pesquisa; iii) coleta de dados; iv) abordagem do problema; v) resultados; vi) população e amostra; e, vii) instrumento de intervenção.

i) Quanto à natureza do objetivo, a estratégia de pesquisa adotada neste trabalho é exploratória e descritiva. É exploratória porque objetiva selecionar informações sobre avaliação de desempenho no contexto internacional, e descritiva porque descreve o processo utilizado para selecionar os artigos do portfólio final de publicação.

ii) Quanto à natureza da pesquisa, é classificada como levantamento teórico/ ilustrativo. Para Ferreira e Yoshida (2004, p.533), o "trabalho teórico ilustrado é voltado para a reflexão de um tema, tópico ou conceito teórico, acompanhado de um ou mais casos práticos com a finalidade de 
ilustração". A presente pesquisa busca a reflexão sobre o problema que permeia a procura do referencial teórico em um amplo universo de pesquisa, seguido pelo caso prático da aplicação de um processo estruturado com intuito de selecionar artigos internacionais alinhados com o tema de pesquisa - Avaliação de Desempenho orientada às questões referentes ao desenvolvimento sustentável.

iii) Quanto à coleta de dados, esta foi realizada em fontes de informações secundárias. Os dados secundários são as fontes de pesquisas externas utilizadas para fundamentar o estudo. Nesta pesquisa, utilizaram-se artigos já publicados e disponibilizados gratuitamente nas bases de dados indexadas ao Portal da Coordenação de Aperfeiçoamento de Pessoal de Nível Superior (CAPES).

iv) Em relação à abordagem do problema, define-se que esta é considerada uma pesquisa qualitativa, que se caracteriza por não empregar instrumentos estatísticos. Segundo Richardson (2008, p. 79), "o método qualitativo difere, em princípio, do quantitativo à medida que não emprega um instrumental estatístico como base do processo de análise de um problema" como é o caso do processo para selecionar as bases de dados e palavras-chave de pesquisa.

v) Quanto aos resultados, a pesquisa caracteriza-se como aplicada, pois se observa a realidade e aplica-se processo para responder ao problema de pesquisa.

vi) A população amostral desta pesquisa são as 25 bases de dados, disponibilizados gratuitamente para a pesquisa no Portal CAPES, na área de conhecimento Engenharias e subárea Engenharia de Produção.

vii) $O$ instrumento de intervenção é a ferramenta utilizada para modificar ou não o contexto pesquisado, ou seja, o meio com o qual a pesquisa está sendo realizada. Neste trabalho, o instrumento proposto é o processo ProKnow-C (BORTOLUZZI et al., 2011; LACERDA, ENSSLIN e ENSSLIN, 2011; TASCA et al., 2010), utilizado pelo LabMCDA, na busca do referencial bibliográfico. O processo será tratado especificamente na Seção 2.2 . 


\subsection{Procedimentos metodológicos}

Com o objetivo de investigar bibliografias para construir o arcabouço teórico deste trabalho, buscaram-se, na literatura transitória especializada, artigos científicos relacionados com o tema da pesquisa. Para identificar os artigos alinhados com o tema de pesquisa avaliação de desempenho orientada às questões referentes ao desenvolvimento sustentável, utilizou-se um processo estruturado proposto pelo Laboratório Multicritério de Apoio à Decisão (LabMCDA) para selecionar os artigos que compuseram o portfólio de pesquisa, conforme demonstrado na Figura 1, que trata sobre o processo para seleção da busca do referencial bibliográfico e processo para a análise bibliométrica.

Figura 1- Processo para seleção da busca do referencial bibliográfico e para análise bibliométrica.

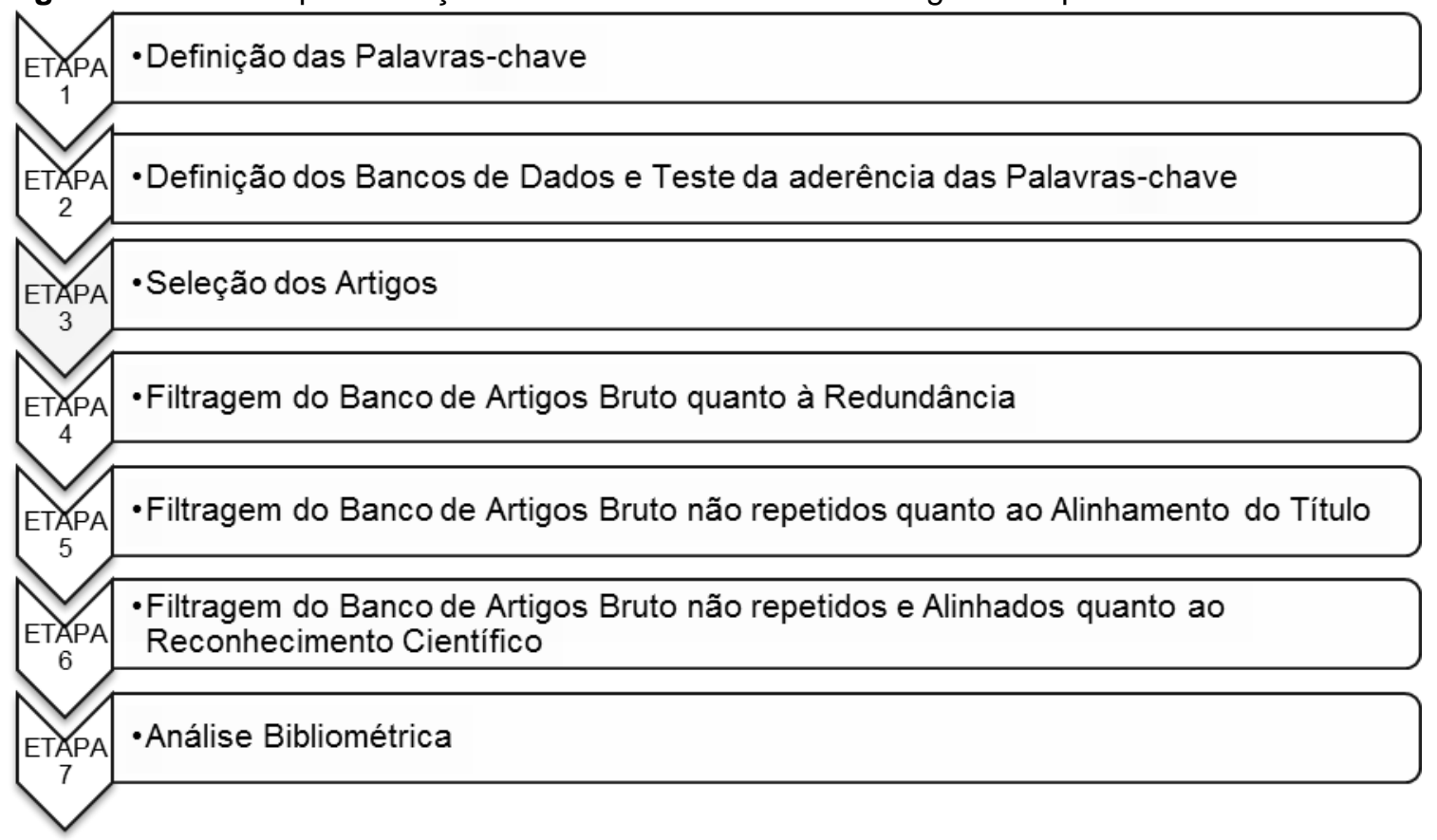

Fonte: Adaptado de Ensslin et al. (2010).

A Figura 1 apresenta o processo proposto para a realização da seleção do portfólio bibliográfico e análise bibliométrica. É realizado em sete fases, sendo elas:

Etapa 1 - Definição das palavras-chave:o processo inicia com a definição das palavras-chave de pesquisa que são identificadas com base no tema/problema, ou seja, nessa fase o autor/pesquisador precisa saber o que pretende pesquisar e a qual problema pretende responder. 


\section{Etapa 2 - Definição dos bancos de dados e teste da aderência das}

palavras-chave: é realizada uma busca aleatória em base de dados de artigos, com reconhecimento científico, alinhados ao assunto pesquisado. O reconhecimento científico é dado pelo número de citações, verificadas no Google Acadêmico (Google Scholar). Essas informações permitem ter um conhecimento adequado das palavras-chave utilizadas nos meios científicos sobre o assunto que se deseja pesquisar. Selecionadas as palavras-chave, estas são testadas em bases de dados selecionadas em forma aleatória. O teste das palavras-chave é realizado em uma ou mais bases de dados, e o resultado da pesquisa aleatória é uma prévia do que deve ser analisado pelo pesquisador/autor que decidirá, com base em suas expectativas, se continuará ou não com os termos testados. Caso o resultado esteja aquém do desejado, deverá recomeçar o processo, a fim de identificar as palavras-chave necessárias para a coleta do material de pesquisa. Se o pesquisador/autor julgar satisfatórios os testes, o próximo passo consiste na seleção das bases de dados alinhados com o tema de pesquisa. Na seleção da base de dados, o pesquisador, de posse das palavras-chave para a condução da pesquisa, acessa o portal, ou banco de dados, disponível e seleciona todas as bases de dados alinhadas com o tema pesquisado. O número de bases selecionadas pode variar de acordo com o tema pesquisado. Escolhidas as bases de dados, procede-se à pesquisa e à quantificação dos artigos encontrados por base de dados.

Etapa 3 - Seleção dos artigos:os artigos encontrados são importados para um software de gerenciamento bibliográfico que auxiliará o pesquisador/autor na apuração do resultado de pesquisa. Como os bancos de dados possuem diversas bases de dados, pode ocorrer de um mesmo artigo estar disponibilizado em mais de uma base de dados de pesquisa.

Etapa 4 - Filtragem do banco de artigos bruto quanto à redundância:após a importação para o gerenciador bibliográfico, ocorre a exclusão dos artigos duplicados. É importante registrar a quantidade de artigos excluídos em cada etapa do processo e o motivo da exclusão. Após a exclusão, a próxima etapa consiste na leitura dos títulos dos artigos alinhados com o tema de pesquisa. Caso a quantidade da amostra seja acima de 10.000 (dez mil) artigos, o processo permite a utilização de palavras de exclusão que auxiliem na redução da amostra. Palavras de exclusão são termos que estão fora do contexto pesquisado. Cabe registrar que a utilização 
de palavras de exclusão é facultativa, e o pesquisador/autor poderá adotá-las ou não.

Etapa 5 -Filtragem do banco de artigos bruto não repetidos quanto ao alinhamento do título: os artigos não alinhados com o tema de pesquisa são retirados (excluídos) dobanco de artigos bruto.

Etapa 6 -Filtragem do banco de artigos bruto não repetidos e alinhados quanto ao reconhecimento científico: os artigos selecionados são analisados em termos de representatividade científica, que consiste na verificação do número de citação de cada artigo no site do Google Acadêmico. Nessa etapa, são préselecionados os artigos com maior número de citação. No caso, essa representatividade é arbitrada pelo pesquisador. Neste trabalho fixou-se a representatividade para aproximadamente $60 \%$ do total de citações encontradas na amostra. Os artigos que possuem representatividade da amostra são classificados como artigos candidatos à inclusão no portfólio final de pesquisa, sendo agrupados no repositório $\mathrm{K}$. Os demais artigos passam a ser denominados de artigos candidatos à exclusão por terem baixa representatividade científica e são tratados num segundo momento, sendo agrupados no repositório $\mathrm{P}$. Nos artigos candidatos à inclusão (pré-selecionados), procede-se à leitura dos resumos e/ou conteúdo com intuito de buscar artigos alinhados com o tema de pesquisa. Caso o resumo, ou artigo pré-selecionado em termos de reconhecimento acadêmico, não seja alinhado com o tema, é excluído da amostra. Após a exclusão dos artigos não alinhados, passa-se a analisar os artigos candidatos à exclusão em termos de alinhamento e relevância dos autores pesquisados. Dessa forma, serão incluídos os artigos com baixa representatividade científica da amostra caso esse artigo esteja alinhado, seja recente e possua autor que faça parte dos artigos que estão no repositório $P$. Após a aplicação dos filtros citados, o autor/pesquisador possuirá um conjunto de artigos com potencial para contribuir para sua pesquisa. É verificada, também, a disponibilidade dos artigos para consulta.

Etapa 7 - Análise bibliométrica: Essa análise é realizada na amostra final de artigos que compõem o constructo teórico de pesquisa, consistindo de três etapas: (i) artigos do portfólio bibliográfico; (ii) referências bibliográficas dos artigos do portfólio bibliográfico pesquisados; e, (iii) artigos do portfólio bibliográfico e referências dos artigos do portfólio bibliográfico. No processo proposto, a análise 
bibliométrica objetiva fornecer subsídios ao pesquisador/autor, para que ele possa analisar e traçar um perfil da publicação adotada na elaboração do constructo teórico de pesquisa.

\section{ANÁLISE E DISCUSSÃO DE RESULTADOS}

A aplicação do método ProKnow-C (BORTOLUZZI et al., 2011, LACERDA, ENSSLIN e ENSSLIN, 2011; TASCA et al., 2010) compreendeu nos seguintes processos: (i) Processo para Seleção do Portfólio Bibliográfico; e, (ii) Processo para Análise Bibliométrica.

\subsection{Processo para Seleção do Portfólio Bibliográfico}

O Processo para Seleção do Portfólio Bibliográfico consiste na identificação dos artigos científicos mais relevantes para o tema de pesquisa, considerando as delimitações estabelecidas pelo pesquisador. No caso do presente artigo, o tema de pesquisa refere-se à avaliação de desempenho orientada às questões referentes ao desenvolvimento sustentável. A seguir são explicitadas as suas etapas.

\subsubsection{Etapa 1 - Definição das Palavras-chave}

Antes de iniciar a busca pelos artigos, definiram-se, primeiramente, os eixos de pesquisa. Chamou-se de Eixo 1 àquele que remetia à avaliação de desempenho e, de Eixo 2 àquele que remetia ao desenvolvimento sustentável. Após a definição dos eixos, arbitrou-se um conjunto de palavras-chave para cada um deles. Para o Eixo 1, foram as seguintes: performance appraisal, performance assessment, performance evaluation e performance measurement. Para o Eixo 2, foram as seguintes: sustainability, sustainable, sustainable development e sustain.

\subsubsection{Etapa 2 - Definição dos Bancos de Dados e Teste da aderência das Palavras-chave}

A definição dos bancos de dados a serem utilizados foi realizada de acordo com alguns critérios estabelecidos pelos pesquisadores. O primeiro critério foi o de 
utilizar os bancos de dados que pudessem ser acessados através do site da Coordenação de Aperfeiçoamento Pessoal de Ensino Superior (CAPES), devido o seu reconhecimento pela comunidade científica brasileira. A CAPES organiza as bases de dados por áreas e, subáreas de conhecimento. A partir da sua classificação, arbitrou-se a área das Engenharias e, como subárea a Engenharia de Produção, para selecionar as bases de dados. Das vinte e cinco bases apresentadas, duas eram de patentes e seis estavam associadas a outras bases. Com isso, verificaram-se dezessete bases potenciais que ofereciam acesso a textos completos e/ou resumos. O terceiro critério foi estabelecer a representatividade no número de artigos encontrados a partir da combinação das palavras-chave entre o Eixo 1 e Eixo 2. Arbitrou-se a representatividade para duzentos artigos em cada base. Dentre as bases pesquisadas, apenas as seguintes alcançaram a representatividade estabelecida: EBSCO, Web of Knowledge, Science Direct e Scopus.

Antes de iniciar a pesquisa definitiva da base de dados, foram realizados testes para verificar a aderência entre o Eixo 1 e o Eixo 2. Nos testes, constatou-se que as palavras-chave utilizadas restringiam a busca de artigos e não permitiam um alinhamento satisfatório, na percepção dos pesquisadores. A partir da análise de alguns dos artigos pesquisados, notou-se que o uso do termo indicators como uma palavra-chave utilizada para expressar a avaliação de desempenho no contexto do desenvolvimento sustentável. Assim, considerou-se que esse termo poderia contribuir na busca de artigos e para o alinhamento desejado, ao ser adicionado ao Eixo 1. O que se mostrou positivo ao repetir uma nova busca. Verificou-se um considerável incremento nos resultados dos artigos encontrados e um melhor alinhamento.

Com relação ao Eixo 2, a partir de uma análise das palavras arbitradas, percebeu-se que muitas das buscas com o s termos sustainable development e sustainable remeteram aos mesmos artigos, sendo a primeira um subconjunto da segunda. Com isso, optou-se somente pelo termo sustainable (no caso, um adjetivo), pois poderia abrir um leque para diversos substantivos (tais como process, consume, analysis, management, development, project etc.). A palavra sustainability mostrou-se contribuir na busca dos artigos e permaneceu no Eixo 2. A palavra sustain, contribuiu muito pouco para as buscas e optou-se por retirá-la do Eixo 2. 
Foram cogitadas outras palavras, tais como, ecological impact, social impact, economic impact, dentre outras, que não contribuíram para incrementar a busca de artigos a ponto de serem inseridas no Eixo 2.Concluiu-se, portanto, que as duas palavras sustainable e sustainability seriam suficientes para a composição do Eixo 2. O quadro 3 apresenta os eixos de pesquisa e as palavras-chave definidas.

Quadro 3 - Palavras-chave definidas para o Eixo 1 e o Eixo 2

\begin{tabular}{|c|c|}
\hline EIXO 1: AVALIAÇÃO DE DESEMPENHO & $\begin{array}{c}\text { EIXO 2: DESENVOLVIMENTO } \\
\text { SUSTENTÁVEL }\end{array}$ \\
\hline Performance Appraisal & Sustainability \\
Performance Assessment & Sustainable \\
\hline Performance Evaluation & \\
\hline Performance Mesasurement & \\
\hline Indicators & \\
\hline
\end{tabular}

Fonte: Da pesquisa (2011)

\subsubsection{Etapa 3 - Seleção dos artigos}

Com os resultados obtidos com essa nova calibragem, realizaram-sebuscas, novamente, para as dezessete bases iniciais. No entanto, dessa vez, estabeleceram-se restrições quanto ao ano de publicação, que passou a considerar artigos publicados a partir de 2001 e quanto aos campos de busca, considerando-se o título, resumos e palavras-chave. Apenas as quatro bases mencionadas anteriormente, retornaram mais de duzentos artigos em seus resultados. O Quadro 4 apresenta o total de artigos encontrados para cada uma das quatro bases. Os artigos encontrados passaram a compor o que se denominou de banco de artigos bruto.

Quadro 4 -Total de artigos encontrados nas bases de dados pesquisadas

\begin{tabular}{|r|c|}
\hline Base de Dados & Total de Artigos \\
\hline EBSCO & 1.242 \\
\hline Science Direct & 1.362 \\
\hline Scopus & 4.117 \\
\hline Web of Knowledge & 2.402 \\
\hline Total Geral & $\mathbf{9 . 1 2 3}$ \\
\hline
\end{tabular}

Fonte: Da pesquisa (2011) 


\subsubsection{Etapa4 - Filtragem do Banco de Artigos Bruto quanto à Redundância}

Os 9.123 artigos encontrados foram importados para um gerenciador bibliográfico. Após a importação, excluíram-se os documentos que não eram de cunho científico e os artigos duplicados. Essas ações resultaram em uma redução de 4.004 artigos. O total de artigos pesquisados passou para 5.119.

\subsubsection{Etapa5 - Filtragem do Banco de Artigos Bruto não repetidos quanto ao Alinhamento do Título}

Logo após, procedeu-se à leitura dos títulos, selecionando-se os artigos alinhados com o tema da pesquisa. Para efeito deste trabalho, ficou estabelecida a seguinte convenção para alinhamento: avaliação de desempenho do desenvolvimento sustentável e indicadores de desenvolvimento sustentável. Como resultado desse filtro, dos 5.119 artigos restou 893para compor o portfólio desta pesquisa.

\subsubsection{Etapa6 - Filtragem do Banco de Artigos Bruto não repetidos e Alinhados quanto ao Reconhecimento Científico}

O critério arbitrado para determinar o reconhecimento científico foi o número de citações do artigo. Para obter o número de citações de cada um dos 893 artigos utilizou-se o site do Google Acadêmico. Após a obtenção da citação dos artigos, foi construída uma curva $A B C$, a fim dividir os artigos em dois repositórios. Arbitrou-se uma representatividade de $60 \%$ do total das citações. O repositório que recebeu os artigos mais citados foi denominado de repositório K. Identificaram-se 58 artigos que continham 40 citações ou mais, pertencentes a esse repositório. Os demais 835 artigos, foram agrupados no repositório $\mathrm{P}$.

Para os artigos que compunham o repositório $\mathrm{K}$, construiu-se uma planilha chamada de banco de autores. Foram identificados 138 autores. Os artigos agrupados no repositório $\mathrm{K}$, foram os candidatos a compor a base final de artigos, chamada de portfólio bibliográfico.Após a leitura dos resumos desses58 artigos mais citados, excluiu-se 32 artigos considerados como desalinhados com a avaliação do 
desenvolvimento sustentável ou indicadores do desenvolvimento sustentável, resultando num portfólio bibliográfico de 26 artigos, a princípio.

Para os 893 artigos que compunham o repositório $P$, realizou-se uma filtragem quanto ao ano de publicação. Identificou-se 292 artigos com publicação há menos de dois anos.Para os 543 artigos restantes, com publicação há mais de dois, verificou-se se os autores desses artigos faziam parte do banco de autores do repositório K. Identificou-se31 artigos cujos autores desses artigos também faziam parte do banco de autores do repositório K. Dos 323 artigos restantes (292 referentes aos artigos publicados há menos de dois anos e 31 artigos publicados há mais de dois anos, cujos autores faziam parte do banco de autores do repositório K), realizou-se uma leitura mais rigorosa dos resumos para verificação do seu alinhamento com a pesquisa. Com isso, identificou-se 2 artigos que passaram a fazer parte do portfólio bibliográfico. Com a incorporação desses 2 artigos, a base final de 26 artigos passou a contar com 28 artigos. Após a seleção, buscaram-se os artigos para análise, disponibilizados com textos completos e gratuitos. Nessa fase, foram excluídos 15 artigos que não estavam disponibilizados de forma completa ou gratuita. Diante disso, o portfólio final desta pesquisa foi composto por 13 artigos científicos, apresentados na Tabela 1. 
Tabela 1 - Portfólio bibliográfico

\begin{tabular}{|c|c|c|c|c|}
\hline AUTOR & ANO & TITULO & JOURNAL & $\begin{array}{c}\text { № } \\
\text { CITAÇÕES } \\
\end{array}$ \\
\hline G. Miller & 2001 & $\begin{array}{l}\text { The development of indicators for sustainable tourism: Results } \\
\text { of a Delphi survey of tourism researchers }\end{array}$ & Tourism Management & 158 \\
\hline F. Figge and T. Hahn & 2004 & $\begin{array}{l}\text { Sustainable Value Added - Measuring corporate contributions } \\
\text { to sustainability beyond eco-efficiency }\end{array}$ & Ecological Economics & 132 \\
\hline $\begin{array}{l}\text { V. Veleva and M. } \\
\text { Ellenbecker }\end{array}$ & 2001 & $\begin{array}{l}\text { Indicators of sustainable production: Framework and } \\
\text { methodology }\end{array}$ & $\begin{array}{l}\text { Journal of Cleaner } \\
\text { Production }\end{array}$ & 88 \\
\hline $\begin{array}{l}\text { C. Labuschagne, A. C. } \\
\text { Brent and R. P. G. van } \\
\text { Erck }\end{array}$ & 2005 & Assessing the sustainability performances of industries & $\begin{array}{l}\text { Journal of Cleaner } \\
\text { Production }\end{array}$ & 85 \\
\hline H. Bossel & 2001 & $\begin{array}{l}\text { Assessing viability and sustainability: A systems-based } \\
\text { approach for deriving comprehensive indicator sets }\end{array}$ & Conservation Ecology & 76 \\
\hline $\begin{array}{l}\text { S. López-Ridaura, } \mathrm{O} \text {. } \\
\text { Masera and M. Astier }\end{array}$ & 2002 & $\begin{array}{l}\text { Evaluating the sustainability of complex socio-environmental } \\
\text { systems. the MESMIS framework }\end{array}$ & Ecological Indicators & 71 \\
\hline $\begin{array}{l}\text { G. A. Mendoza and R. } \\
\text { Prabhu }\end{array}$ & 2003 & $\begin{array}{l}\text { Qualitative multi-criteria approaches to assessing indicators of } \\
\text { sustainable forest resource management }\end{array}$ & $\begin{array}{l}\text { Forest Ecology and } \\
\text { Management }\end{array}$ & 66 \\
\hline D. Krajnc and P. Glavič & 2005 & A model for integrated assessment of sustainable development & $\begin{array}{l}\text { Resources, Conservation } \\
\text { and Recycling }\end{array}$ & 60 \\
\hline $\begin{array}{l}\text { E. Ronchi, A. Federico } \\
\text { and F. Musmeci }\end{array}$ & 2002 & $\begin{array}{l}\text { A system oriented integrated indicator for sustainable } \\
\text { development in Italy }\end{array}$ & Ecological Indicators & 58 \\
\hline $\begin{array}{l}\text { A. Boggia and } \mathrm{C} \text {. } \\
\text { Cortina }\end{array}$ & 2010 & $\begin{array}{l}\text { Measuring sustainable development using a multi-criteria } \\
\text { model: A case study }\end{array}$ & $\begin{array}{l}\text { Journal of Environmental } \\
\text { Management }\end{array}$ & 43 \\
\hline $\begin{array}{l}\text { H. R. Sahely, C. A. } \\
\text { Kennedy and B. J. } \\
\quad \text { Adams }\end{array}$ & 2005 & $\begin{array}{l}\text { Developing sustainability criteria for urban infrastructure } \\
\text { systems }\end{array}$ & $\begin{array}{l}\text { Canadian Journal of Civil } \\
\text { Engineering }\end{array}$ & 40 \\
\hline N. Moussiopoulos, C. & & & & \\
\hline $\begin{array}{l}\text { Achillas, C. } \\
\text { Vlachokostas, D. } \\
\text { Spyridi and K. } \\
\text { Nikolaou }\end{array}$ & 2010 & $\begin{array}{l}\text { Environmental, social and economic information management } \\
\text { for the evaluation of sustainability in urban areas: A system of } \\
\text { indicators for Thessaloniki, Greece }\end{array}$ & Cities & 1 \\
\hline J. Kondyli & 2010 & $\begin{array}{l}\text { Measurement and evaluation of sustainable development. A } \\
\text { composite indicator for the islands of the North Aegean region, } \\
\text { Greece }\end{array}$ & $\begin{array}{l}\text { Environmental Impact } \\
\text { Assessment Review }\end{array}$ & 3 \\
\hline
\end{tabular}

Fonte: Da pesquisa (2011)

\subsection{Processo para Análise Bibliométrica}

O Processo para Análise Bibliométrica consiste na evidenciação das informações geradas por meio da identificação da(s) variável(eis) e contagem de suas ocorrências em um conjunto definido de artigos (Portfólio Bibliográfico) para promoção de conhecimento científico e de gestão da informação para o tema de pesquisa. No caso do presente artigo, o tema refere-se à avaliação de desempenho no contexto do desenvolvimento sustentável. O Processo para Análise Bibliométrica apresentou os seguintes subprocessos:

- Artigos do portfólio bibliográfico;

- Referências dos artigos do portfólio bibliográfico; e,

- Artigos do Portfólio e Referências dos Artigos do Portfólio.

Revista Produção Online, Florianópolis, SC, v.13, n. 4, p. 1198-1226, out./dez. 2013. 


\subsubsection{Artigos do portfólio bibliográfico}

O subprocesso Artigos do portfólio bibliográfico proporcionou as seguintes informações:

- Estimar o grau de relevância dos periódicos (Figura 2);

- Estimar reconhecimento científico dos artigos (Figura 3);

- Estimar o grau de relevância dos autores (Figura 4); e,

- Estimar palavras mais utilizadas (Figura 5).

Figura 2

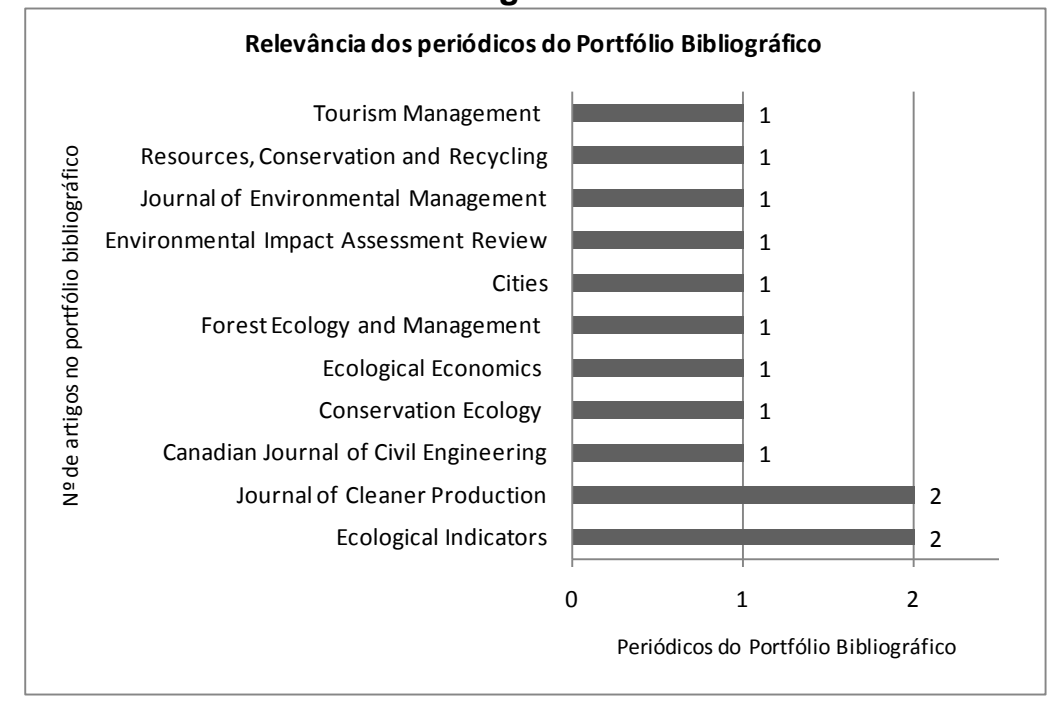

Observou-se na Figura 2, que os artigos integrantes do portfólio bibliográfico contemplados em certos periódicos científicos, não apresentam uma concentração de publicações sobre o tema de pesquisa. Os periódicos Ecological Indicators e Journal of Cleaner Production apresentaram o maior número de publicações sobre o tema de pesquisa. 
Figura 3

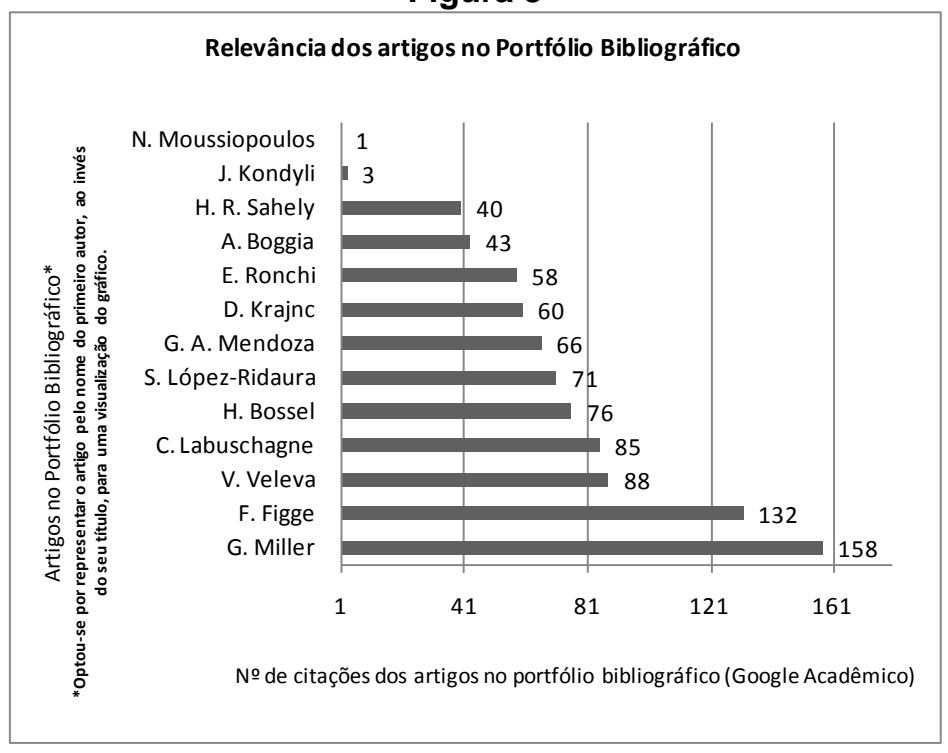

Observaram-se na Figura 3, que 70\% dos artigos do portfólio bibliográfico se concentram na faixa entre 40 e 90 citações. Os dois artigos mais citados foram "The development of indicators for sustainable tourism: Results of a Delphi survey of tourism researchers" e "Sustainable Value Added - Measuring corporate contributions to sustainability beyond eco-efficiency".

\section{Figura 4}

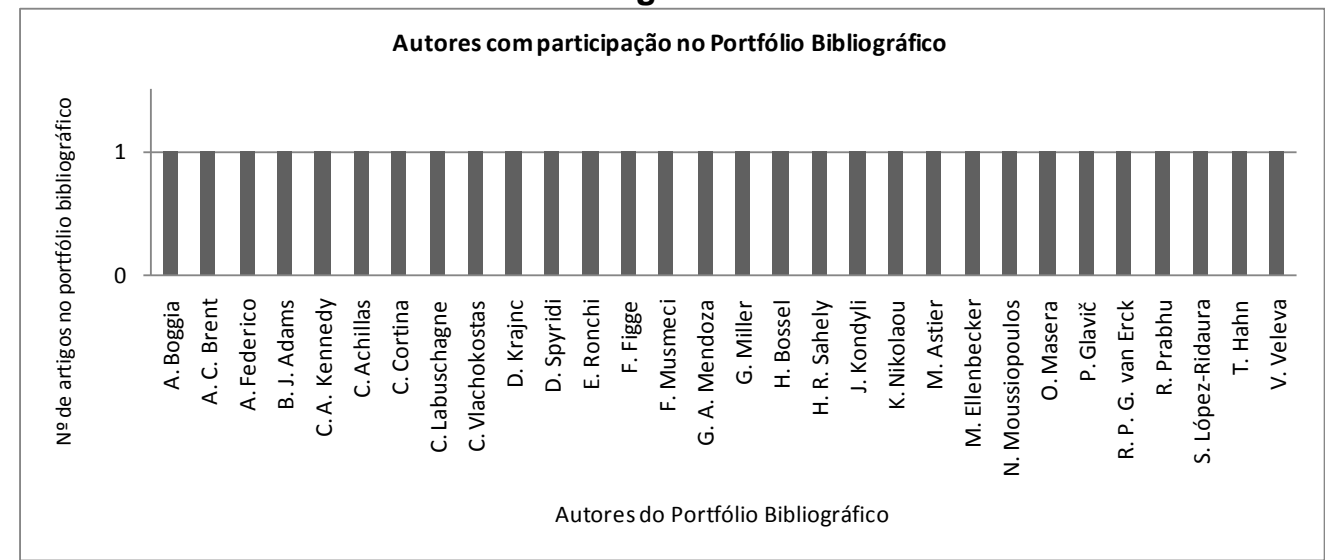

Observou-se na Figura 4, que entre os artigos que compõem o portfólio bibliográfico, não foi identificado um autor que pudesse se destacar dentre os demais. 
Figura 5

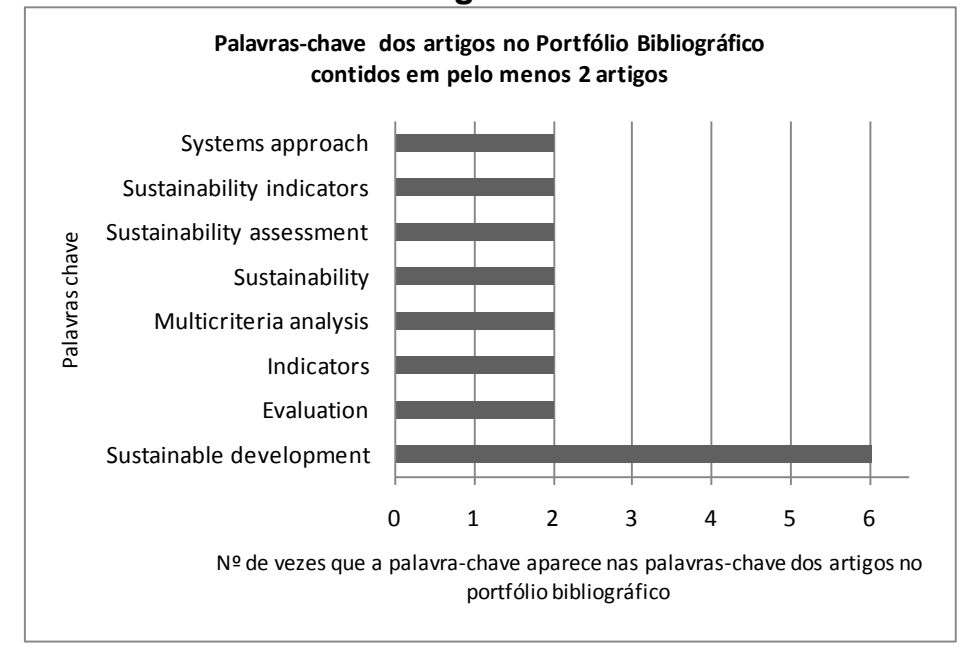

Observou-se, na Figura 5, que houve um alinhamento das palavras referentes ao eixo 2. Com relação ao eixo 1, percebe-se que a maior ocorrência dos termos deu-se de forma desmembrada. O acréscimo do quinto termo indicators proporcionou melhor alinhamento para expressar a avaliação de desempenho orientada às questões do desenvolvimento sustentável.

\subsubsection{Referências dos artigos do portfólio bibliográfico}

O subprocesso Referências dos artigos do portfólio bibliográfico proporcionou as seguintes informações:

- Estimar o grau de relevância dos periódicos (Figura 6);

- Estimar reconhecimento científico dos artigos (Figura 7); e,

- Estimar o grau de relevância dos autores (Figura 8).

Figura 6

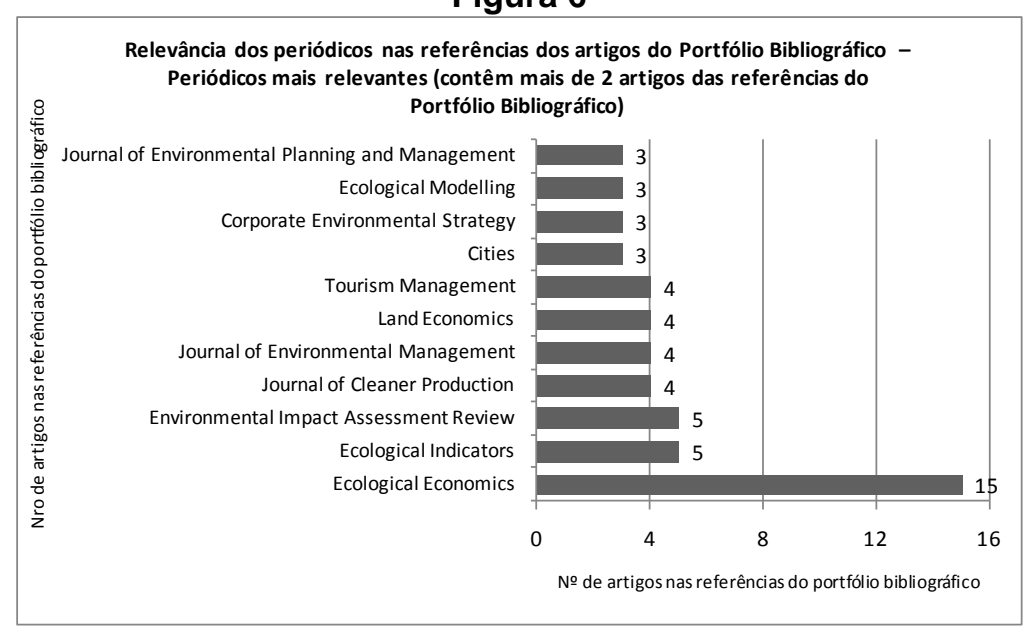

Revista Produção Online, Florianópolis, SC, v.13, n. 4, p. 1198-1226, out./dez. 2013. 
Observou-se, na Figura 6, que as referências dos artigos do portfólio bibliográfico estão dispersos em muitos periódicos. No entanto, pode-se destacar o periódico Ecological Economics, com maior relevância.

Figura 7

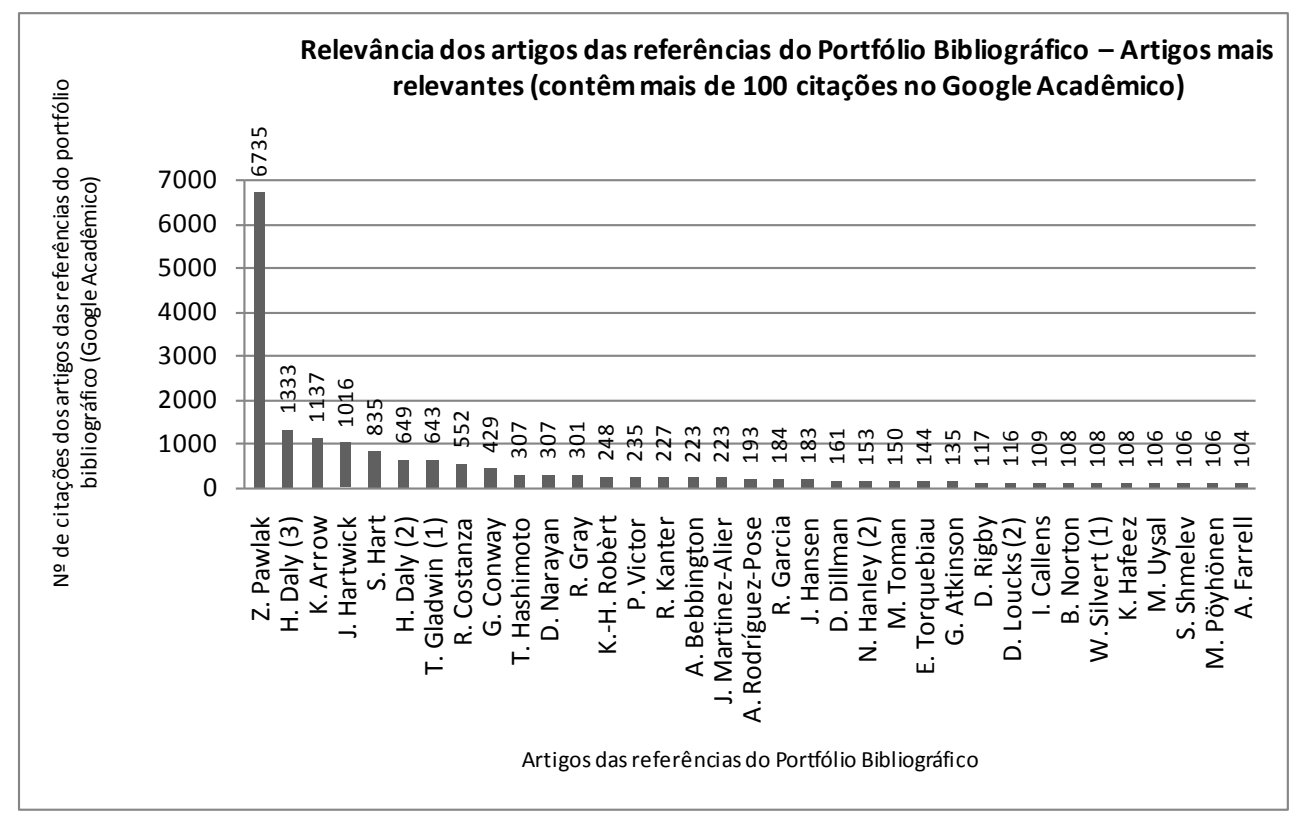

Observou-se na Figura 7, que em relação ao total de 145 referências do portfólio (contando apenas artigos científicos), 24\% destas possuem mais de 100 citações, 28\% possuem entre 40 e 100 citações, 39\% possuem entre 10 e 40 citações e 9\% das referências com menos de 10 citações. Os dois artigos das referências bibliográficas do portfólio identificados como os mais citados foram "Rough Sets" (Z. Pawlak) e "For the Common Good" (H. Daly). 
Figura 8

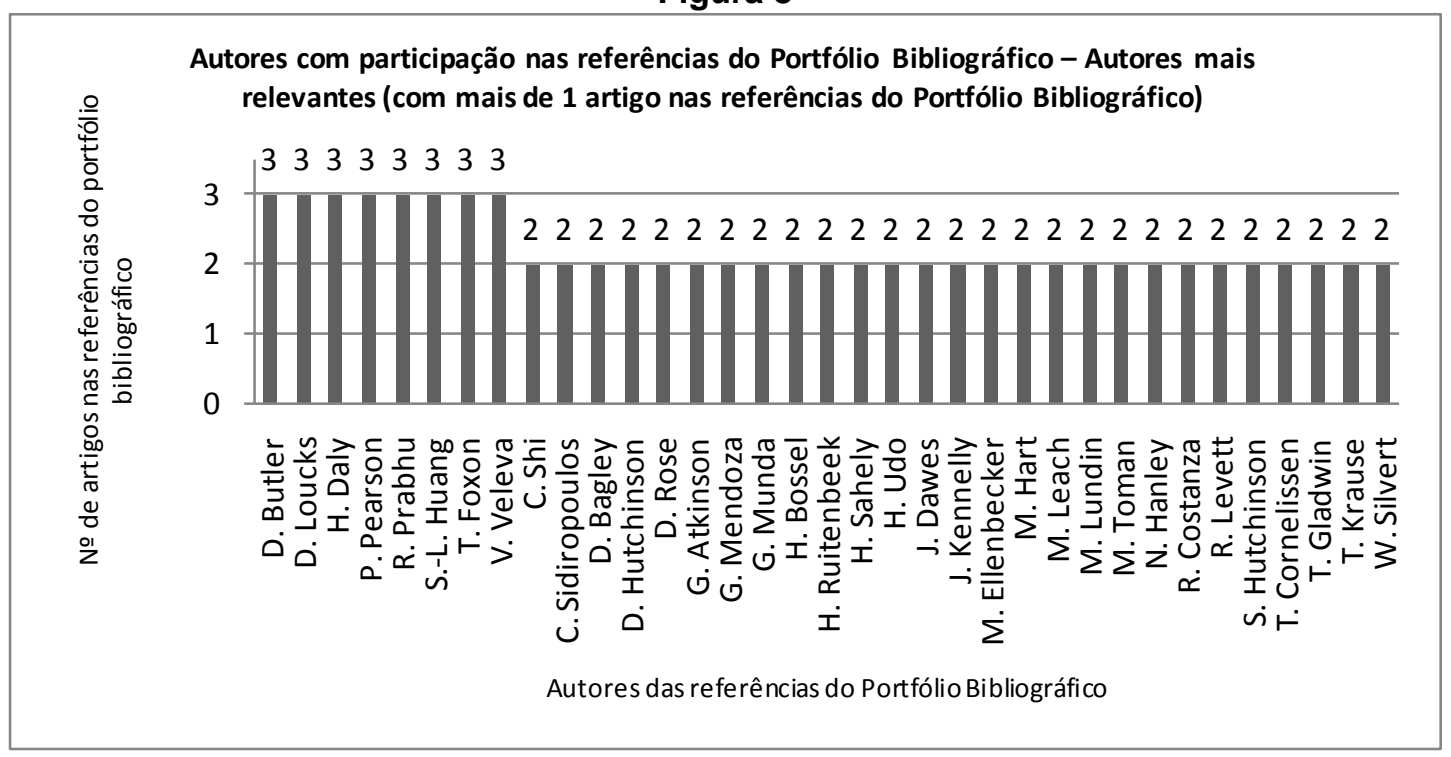

Observou-se, na Figura 8, que os autores que participam das referências do portfólio bibliográfico, com um único artigo, os mais representativos foram D. Butler, D. Loucks, H. Daly, P. Pearson, R. Prabhu, S.-L Huang, T. Foxon e V. Veleva.

\subsubsection{Artigos do portfólio bibliográfico e Referências dos artigos do portfólio bibliográfico}

O subprocesso Artigos do portfólio bibliográfico e Referências dos artigos do portfólio bibliográfico proporcionou a seguinte informação:

- Estimar reconhecimento científico de artigos + Estimar o grau de relevância dos autores (Figura 9).

A Figura 9 visa identificar dentre os artigos selecionados (do portfólio), os de maior relevância acadêmica. De acordo com o processo proposto pelo LABMCDA, a relevância acadêmica é verificada por meio de um exame combinado entre o número de citações dos artigos (Google acadêmico) com o número de citações dos artigos mais citados, nas referências dos artigos no portfólio de pesquisa. O gráfico divide-se em quadrantes demarcados. Essa demarcação pode variar de 5\% (cinco) a $10 \%$ (dez) do total de artigos participantes da amostra final. Por meio da divisão dos quadrantes é possível identificar, para o portfólio: os artigos de destaque; artigos 
de destaque na literatura realizados por autores de destaque; artigos realizados por autores de destaque; e, artigos relevantes para o tema de pesquisa.

\section{Figura 9}

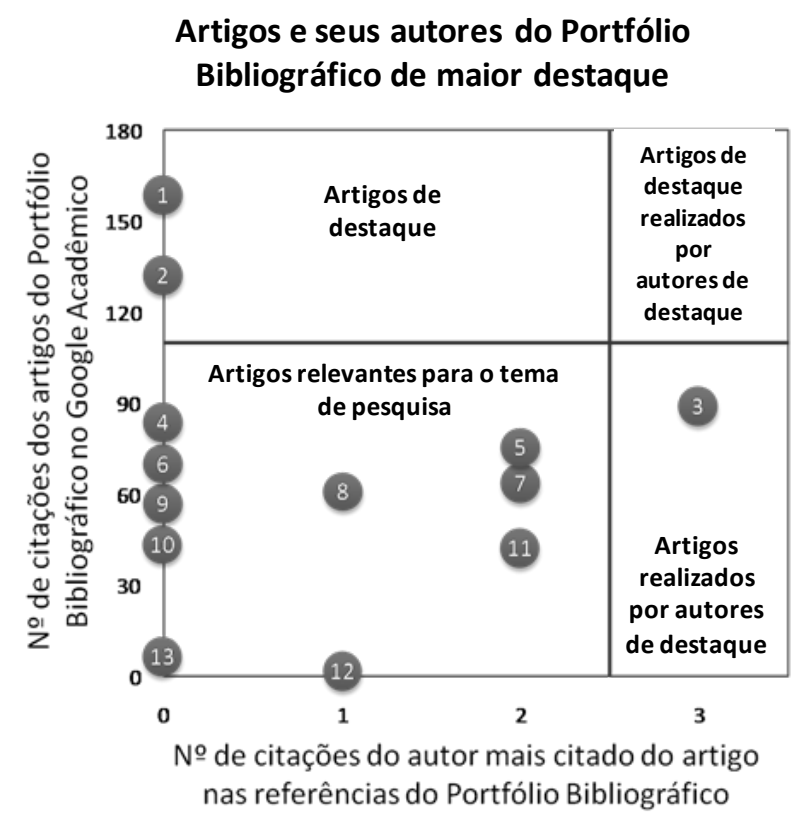

\footnotetext{
1 The development of indicators for sustainable tourism: Results of a Delphi survey of tourism researchers Sustainable Value Added - Measuring corporate contributions to sustainability beyond eco-efficiency Indicators of sustainable production: Framework and methodology Assessing the sustainability performances of industries Assessing viability and sustainability: A systems-based approach for deriving comprehensive indicator sets Evaluating the sustainability of complex socioenvironmental systems. the MESMIS framework Qualitative multi-criteria approaches to assessing indicators of sustainable forest resource management A model for integrated assessment of sustainable development

A system oriented integrated indicator for sustainable development in Italy

10 Measuring sustainable development using a multi-

10 criteria model: A case study

11 Developing sustainability criteria for urban infrastructure systems

2 Environmental, social and economic information management for the evaluation of sustainability in urban areas: A system of indicators for Thessaloniki, Greece

13 Measurement and evaluation of sustainable development. A composite indicator for the islands of the North Aegean region, Greece
}

Observou-se, na Figura 9, que no portfólio bibliográfico foram encontrados 2 artigos de destaque (em relação ao número de citações) e 1 artigo realizado por autores de destaque, sendo este $\mathrm{V}$. Veleva.

\subsection{Discussão de resultados}

O processo de análise bibliométrica, proposto pelo LabMCDA, proporcionou identificar, por meio do portfólio bibliográfico construído, informações sobre os periódicos, autores, artigos e palavras-chave. Com relação às informações sobre os periódicos dos artigos do portfólio, apontaram-se como os mais relevantes o Journal of Cleaner Production e o Ecological Economics (Figura 2). Para as referências dos artigos do portfólio, apontou-se o Ecological Indicators (Figura 6.).

Com relação aos autores dos artigos do portfólio bibliográfico, não se identificaram autores que se destacassem entre os demais (aparecendo em mais de um trabalho) (Figura 4). Já para os autores das referências bibliográficas do 
portfólio, identificaram-se os seguintes autores: D. Butler, D. Loucks, H. Daly, P. Pearson, R. Prabhu, S.-L Huang, T. Foxon e V. Veleva (Figura 8).Com relação aos artigos do portfólio, os dois artigos mais citados, no Google Acadêmico, foram "The development of indicators for sustainable tourism: Results of a Delphi survey of tourism researchers" e "Sustainable Value Added - Measuring corporate contributions to sustainability beyond eco-efficiency" (Figura 3).

A Figura 9 representa a correlação entre a Figura 8 e a Figura 3, apresentando o reconhecimento científico dos artigos do portfólio (pelo número de citações do Google Acadêmico) e a relevância dos autores (pelo número de citações nas referências do portfólio bibliográfico).O resultado ratifica os artigos de destaque evidenciados na Figura 3 e entre os autores analisados na Figura 8, evidenciou-se destaque para $\mathrm{V}$. Veleva.

Já para os artigos das referências bibliográficas do portfólio, os dois mais relevantes foram os seguintes: "Rough Sets" e "For the Common Good" (Figura 7).

Com relação às palavras-chave, evidenciou-se que proporcionaram a construção de um portfólio bibliográfico que estivesse alinhado com o tema de pesquisa (avaliação de desempenho orientado às questões do desenvolvimento sustentável) (Figura 5).

Com relação ao portfólio bibliográfico pesquisado e o construto teórico apresentado na seção 2., é importante fazer as seguintes observações: i) as obras dos autores clássicos (CARSON, 1962; MEADOWS et al.,1972; SACHS, 1993, 2002; e, ELKINGTON,2004) abordadas no constructo teórico, correspondem a publicações permanentes (livros);e, ii) a análise das referências dos artigos do portfólio delimitou-se à bibliografia transitória (artigos científicos). Em função disto, as obras desses autores não aparecem nas estatísticas apresentadas. Entretanto, na leitura dos artigos do portfólio, percebeu-se a influência de suas idéias, evidenciadas pela preocupação, na avaliação de desempenho, com as questões econômicas, sociais e ambientais, que consistem o tema desenvolvimento sustentável. 


\section{CONSIDERAÇÕES FINAIS}

O presente trabalho objetivou construir, no pesquisador, um conhecimento inicial necessário, para iniciar uma pesquisa sobre a avaliação de desempenho orientada às questões referentes ao desenvolvimento sustentável, cientificamente justificado. Dentre os resultados da aplicação da pesquisa, constatou-se que o processo estruturado utilizado, auxiliou os autores a selecionar, dentre de 9.123 títulos disponíveis para pesquisa no Portal Capes, 13 artigos que passaram a servir de suporte à pesquisa.

Cabe ressaltar que este trabalho está limitado à amostra dos periódicos pesquisados e às palavras-chave utilizadas. A análise delimitou-se a artigos científicos, referentes à avaliação de desempenho orientado às questões tratadas no desenvolvimento sustentável, disponibilizados gratuitamente no Portal CAPES.

Finalmente, como recomendação, sugere-se uma padronização mínima das ferramentas de busca das bases de dados disponibilizadas via internet, devido à diversidade existente para as buscas, que dificultam a pesquisa nessas bases, bem como o processo para importação dos resultados das buscas para os softwares de gerenciamento bibliográfico. Isso acaba implicando em um trabalho estressante e demorado para o pesquisador, sendo um empecilho para que possa atender as demandas do ambiente no qual está inserido. Para futuras pesquisas, sugere-se que o processo, aqui ilustrado, seja replicado tanto para o mesmo tema de pesquisa, quanto para outros temas.

\section{REFERÊNCIAS}

ADAMS, C.; FROST, G.; WEBBER, W. Triple bottom line: a review of the literature. In: HENRIQUES, A. (Org.) The triple bottom line: does it all add up? London: Earthscan Publications Ltd, 2004. Cap. 2. p. 17-25.

AGUIRRE, M. S. Sustainable development: why the focus on the population? International Journal of Social Economics. v.29, n.12, p.923-945, 2002.

ALMEIDA, F. Os desafios da sustentabilidade. Rio de Janeiro: Elsevier, 2007. 
BORTOLUZZI, S. C.; ENSSLIN, S. R.; ENSSLIN, L.; VALMORBIDA, S. M. I. A Avaliação de desempenho em redes de pequenas e médias empresas: estado da arte para as delimitações postas pelo pesquisador. R. eletr. estrat. neg., Florianópolis, v.4, n.2, p. 202-222, jun./dez. 2011.

BRUNO, F. S.; BRUNO, A. C. M. O papel do setor têxtil e de confecção brasileiro na liderança de um modelo sustentável de desenvolvimento. Revista Produção Online, v.9, n.3, p. 551-572, 2009.

BYRD, E. T. Stakeholders in sustainable tourism development and their roles: applying stakeholder theory to sustainable tourism development. Tourism Review. v.62, n.2, p.6-13, 2007.

CAPES. Estatísticas de uso. 2010. Disponível em:

<http://www.periodicos.capes.gov.br/index.php?mn=69\&smn=77>. Acesso em: 28 maio 2011.

CARPENTER S.R. et al. Millennium ecosystem assessment: research needs. Science. v.314, n.5797, p. 257 - 258, 2006. DOI: 10.1126/science.1131946.

CARPENTER S.R. et al., Science for managing ecosystem services: beyond the millennium ecosystem.PNAS, v.106, n.5, p.1305-1312, 2009. DOI:

10.1073/pnas.0808772106.

CARSON, R. Silent spring. Houghton Mifflin, Boston, 1962.

DAVIDSON, W. N.; WORRELL, D. L. Regulatory pressure and environmental management infrastructure and practices. Business Society. v.40, n.3, p 315-342, set. 2001.

ELKINGTON, J. Enter the triple bottom line. In: HENRIQUES, A.; RICHARDSON, J. (Org.) The triple bottom line: does it all add up? London: Earthscan Publications Ltd, cap. 1, p.1-16, 2004.

ESTES, R. J. Toward sustainable development: from theory to praxis. Social Development Issues, v. 15, n. 3, p. 1-29, 1993.

FABER, N.; JORNA, R.; VAN ENGELEN, J.The sustainability of "sustainability" - a study into the conceptual foundations of the notion of "sustainability". Journal of Environmental Assessment Policy and Management, v. 7, n. 1, p. 1-33, 2005. 
FERREIRA, N. S; YOSHIDA, E. M. P. Produção Científica sobre psicoterapias breves no Brasil e demais países latino-americanos (1990-2000). Est. Psicol, v. 3, n. 3, p. 523-531, set./dez. 2004.

FERROLI, P.C.M.; LIBRELOTTO, L.I. Integração da sustentabilidade em ferramenta projetual: FEAP-SUS. Revista Produção Online. Florianópolis, SC, v.11, n. 2, p. 447-475, abr./jun., 2011.

GRI. Sustainability reporting guidelines. Global Reporting Initiative. Boston, 2002.

JORGENSEN, T. H.; REMMEN, A.; MELLADO, M. D. Integrated management systems - three different levels of integration. Journal of Cleaner Production, v. 14, p. 713-722, 2006.

KATES, R. W.; PARRIS T.M.; LEISEROWITZ A. A. What is sustainable development: goals, indicators, values and practice. Environment: Science and Policy for Sustainable Development, v. 47, n. 3, p. 9-21, 2005.

KRZYZANOWSKI, R. F.; FERREIRA, M. C. G. Avaliação de periódicos científicos e técnicos brasileiros. Ci. Inf., v.27 n.2, p.165-175, 1998. DOI: 10.1590/S010019651998000200009.

LACERDA, R. T. O., ENSSLIN, L.; ENSSLIN, S. R. Contribuições à gestão estratégica de organizações quando analisados na visão de seu desempenho. Gestão.Org, v.2, 2011.

MEA. Ecosystems and human well-being: synthesis. Washington, DC: Island Press, 2005.

MEADOWS, D.H.; MEADOWS, D.L.; RANDERS, J.; BEHRENS_III, W.W. The limits to growth: a report for the club of rome's project on the predicament of mankind. Universe Books, New York, 1972.

MERLIN, F. K. Análise de convergência dos parâmetros estabelecidos por meio das ferramentas de gestão do padrão ISO à indução do desenvolvimento sustentável nas organizações. 2011. 239f. Dissertação (Mestrado em Engenharia de Produção) - Programa de Pós- Graduação em Engenharia de Produção, UFSC, Florianópolis, 2011.

MORIOKA, T.; SAITO, O.; YABAR, H. The pathway to a sustainable industrial society - initiative of the Research Institute for Sustainability Science (RISS) at Osaka University. Sustain Sci, v.1, p.65-82, 2006. 
NOGUEIRA, A. C.; PERES, A. P.; CARVALHO, E. M.Avaliação do risco ambiental utilizando fmea em um laticínio na região de lavras - MG. Revista Produção Online, v.11, n.1, p. 194-209, mar., 2011.

PEZZEY, J. Sustainable development concepts. Washington, DC: The World Bank, 1992.

REED, M. S.; FRASER, E. D.G.; DOUGILL, A. J.An adaptive learning process for developing and applying sustainability indicators with local communities. Ecological Economics. v. 59, p. 406-418, 2006.

REES, W. E. Economic development and environmental protection: an ecological economics perspective. Environmental Monitoring and Assessment. B6, p.29-45, 2003.

RICHARDSON, Roberto Jarry. Pesquisa social: métodos e técnicas. São Paulo: Atlas, 2008.

ROBÈRT, K. -H. et al. Strategic sustainable development: selection, design and synergies of applied tools. Journal of Cleaner Production, v. 10, p. 197-214, 2002.

ROSA, F. S.; ENSSLIN, S. R.; ENSSLIN, L. Evidenciação ambiental: processo estruturado de revisão de literatura sobre avaliação de desempenho da evidenciação ambiental. Sociedade, Contabilidade e Gestão (UFRJ). v.4, p.4-8, 2009.

SACHS, I. Caminhos para o desenvolvimento sustentável. Rio de Janeiro: Garamond, 2002.

SACHS, I. Desenvolvimento: includente, sustentável, sustentado. Rio de Janeiro: Garamond, 2004. 151p.

SACHS, I. Estratégias de transição para o século XXI: desenvolvimento e meio ambiente.São Paulo: Studio Nobel: Fundap, 1993. 103p.

SALIH, T. M. Sustainable economic development and the environment. International Journal of Social Economics, v.30, n.1-2, p.153-162, 2003.

SHARFMAN, M. P.; SHAFT, T. M.; TIHANYI, L. A model of the global and institutional antecedents of high-level corporate environmental performance.

Business Society, v.43, n.1, p 6-36, mar. 2004.

SOUZA, J. V. Processo para avaliar periódicos científicos: proposta e ilustração para a revista contemporânea de contabilidade. 2010. 331f. Dissertação (Mestrado 
em Contabilidade) - Programa de Pós- Graduação em Contabilidade, UFSC, Florianópolis, 2010.

SUSTAINABILITY COMPENDIUM. Social and environmental responsibility management tools. São Paulo, 2007. 184p. Disponível em:

<http://www.institutoatkwhh.org.br/compendio/pdf/compendium.pdf> Acesso em: 09 nov. 2010.

TASCA, J. E.; ENSSLIN, L.; ENSSLIN, S. R.; ALVES, M. B. M. An approach for selecting a theoretical framework for the evaluation of training programs. Journal of European Industrial Training, v. 34, n.7, p. 631 - 655, 2010.

TRIM, P. R. J.; LEE, Y. A strategic approach to sustainable partnership development. European Business Review. v.20, n.3, p.222-239, 2008.

VALENTE, S. Sustenaible development, renewable resources and techonogicalprogresss. Evironmental \& Resource Economics, v.30, p.115-125, 2005

VEIGA, J. E. da. Desenvolvimento sustentável: o desafio do século XXI. 3. ed. Rio de Janeiro: Garamond, 2008, 220p.

ZWETSLOOT, G. I. J. M. From management systems to corporate social responsability. Journal of Business Ethics. v. 44, n. 2-3, p. 201-207, 2003.

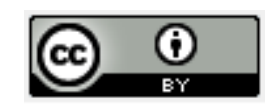

Artigo recebido em 17/06/2011 e aceito para publicação em 07/08/2012. 